\title{
Severe Proximal Myopathy with Remarkable Recovery after Vitamin D Treatment
}

\author{
Yousef A. Al-Said, Hiyam S. Al-Rached, Hussien A. Al-Qahtani, \\ Mohammed M.S. Jan
}

\begin{abstract}
Background: Osteomalacia is an uncommon cause of muscle weakness. Our objectives were to describe features of myopathy associated with Vitamin D deficiency and examine the contributing factors leading to osteomalacic myopathy in our region. Methods: Patients identified retrospectively for the six year period ending in December 2006 with the diagnosis of osteomalacia and/or Vitamin D deficiency associated proximal muscle weakness were included. They were followed in three major centers in western Saudi Arabia. Clinical, biochemical, radiological, and electrophysiological findings were collected before and after Vitamin D treatment by chart review. Results: Forty seven female patients aged 13-46 years (mean 23.5, SD 4.5) were included. All were veiled and covered heavily when outside the house for social and cultural reasons. Only eight (17\%) had adequate varied diet with daily milk ingestion. All patients presented with progressive proximal muscle weakness lasting 6-24 months (mean 14) prior to our evaluation. The weakness was severe in six (13\%) patients leading to wheel chair bound states. Associated musculoskeletal pain involving the back, hips, or lower limbs was common (66\%). Osteomalcia was the referral diagnosis in only 11 patients and the remaining $36(77 \%)$ patients were misdiagnosed. All patients had metabolic and radiological profiles suggestive of osteomalacia. Remarkable recovery was documented in all patients following oral cholecalciferol and calcium supplementation. Conclusions: Vitamin D deficiency is an important treatable cause of osteomalacic myopathy in Saudi Arabia. The diagnosis is frequently delayed or missed. Screening for Vitamin D deficiency in patients with acquired myopathy is needed to identify this treatable disorder.
\end{abstract}

RÉSUMÉ: Récupération remarquable d'une myopathie proximale sévère suite au traitement par la vitamine D. Contexte : L'ostéomalacie est une cause rare de faiblesse musculaire. Nos objectifs étaient de décrire les caractéristiques de la myopathie associée à un déficit en vitamine D et d'examiner les facteurs qui contribuent à la myopathie ostéomalacique dans notre région. Méthodes : Les patients ont été identifiés rétrospectivement sur une période de 6 ans se terminant en décembre 2006. Le critère d'inclusion était un diagnostic d'ostéomalacie et/ou de déficit en vitamine D associé à une faiblesse musculaire proximale. Ces patients étaient suivis dans trois grands centres de l'ouest de l'Arabie Saoudite. Les dossiers ont été révisés et les observations cliniques, biochimiques, radiologiques et électrophysiologiques ont été recueillies avant et après le traitement par la vitamine D. Résultats : Quarante-sept patientes entre 13 et 46 ans (moyenne 23,5, écart type 4,5) ont été incluses dans l'étude. Toutes étaient voilées et lourdement vêtues pour des raisons sociales et culturelles quand elles sortaient de leur demeure. Seulement 8 d'entre elles (17\%) avaient une diète variée et adéquate, avec ingestion quotidienne de lait. Toutes ont consulté pour une faiblesse musculaire proximale progressive présente depuis 6 à 24 mois (moyenne 14 mois) au moment de notre évaluation. La faiblesse était sévère chez 6 patientes (13\%), au point que ces femmes étaient confinées à un fauteuil roulant. Des douleurs musculosquelettiques au dos, aux hanches ou aux membres inférieurs étaient présentes chez $66 \%$ des patientes. Un diagnostic d'ostéomalacie avait été posé chez seulement 11 patientes au moment où elles avaient été dirigées à un spécialiste et le diagnostic était erroné chez les 36 autres patientes (77\%). Toutes les patientes avaient un profil métabolique et radiologique qui suggérait ce diagnostic. Une récupération remarquable a été observée chez toutes les patientes suite à la prise d'un supplément oral de cholécalciférol et de calcium. Conclusions : Un déficit en vitamine D est une cause traitable importante de myopathie ostéomalacique en Arabie Saoudite. Le diagnostic est souvent posé tardivement ou manqué. Le dépistage du déficit en vitamine $\mathrm{D}$ chez les patients présentant une myopathie acquise est essentiel pour identifier cette maladie traitable.

Can. J. Neurol. Sci. 2009; 36: 336-339

Osteomalacia is an uncommon cause of muscle weakness ${ }^{1-3}$. However, myopathy is relatively common in osteomalacia and may be the initial feature in up to $30 \%$ of patients ${ }^{4}$. Vitamin D deficiency is the most common cause of osteomalacia. Vitamin D3 (cholecalciferol) is synthesized nonenzymatically in the skin from 7-dehydrocholesterol during exposure to ultraviolet rays in sunlight. Vitamin D deficiency can be caused by unusually low
From the Department of Neurosciences (YAAS, HSAR, MMSJ), King Faisal Specialist Hospital \& Research Center; Department of Internal Medicine (HAAQ), King Abdulaziz Medical City; Department of Pediatrics (MMSJ), King Abdulaziz University Hospital, Jeddah, Saudi Arabia.

Received October 7, 2008. Final Revisions Submitted January 19, 2009. Correspondence to: Mohammed M.S. Jan, Pediatric Neurology, Department of Neurosciences, King Faisal Specialist Hospital \& Research Center, MBC J-76, PO Box 40047, Jeddah 21499, Kingdom of Saudi Arabia. 
sun exposure combined with lack of Vitamin D fortified foods or malabsorption. Alternatively, impaired hydroxylation of vitamin $\mathrm{D}$ in liver or kidney can prevent the metabolism of Vitamin D into the physiologically active form. Although sunshine is abundant in Saudi Arabia throughout the year, exposure to sunlight is avoided by local population due to excessive heat and socio-cultural reasons. Almost all people use head cover and Saudi women in particular adopt a strict clothing code covering most of their body when they leave their homes ${ }^{5}$. This causes an extra burden to the calcium balance in addition to the effects of high parity and prolonged breast feeding ${ }^{6}$. Therefore, Vitamin D deficiency is not unusual in our community, especially for women during their reproductive years ${ }^{7}$. Subclinical Vitamin D deficiency is even more common, preceding the clinical symptoms and signs of osteomalacia ${ }^{8}$. This was documented in several Saudi studies showing low Vitamin D levels in women who tend to avoid sunlight and remain fully covered outdoors ${ }^{5-9}$. In our experience, osteomalacia is under recognized as a cause of myopathy in our population leading to diagnostic delays or misdiagnosis. Our objectives are to describe the features of myopathy associated with Vitamin D deficiency and examine the contributing factors leading to osteomalacic myopathy in our region.

\section{METHODS}

Patients identified retrospectively for the six year period ending in December 2006 with the diagnosis of osteomalacia and/or Vitamin D deficiency associated proximal muscle weakness were included. Patients were included from neurology outpatient department or electromyography clinics in three major centers of western Saudi Arabia, including King Faisal Specialist Hospital \& Research Center, King Abdulaziz Medical City, and King Fahad General Hospital, all in Jeddah, Saudi Arabia. All patients were evaluated and followed by a certified neurologist. The clinical symptoms and signs were documented in addition to detailed history including family and social circumstances. Inquiry about sunlight exposure and detailed dietary history were included. Clinical and neurological examination documenting proximal myopathy and any other relevant systemic or neurological findings were recorded. Biochemical, radiological, and electrophysiological data were collected before and after Vitamin D treatment by chart review. To diagnose osteomalacia, patients had at least two of the following abnormalities: low plasma calcium, low plasma phosphate, elevated alkaline phosphatase, or a radiographic finding suggestive of osteomalacia ${ }^{10}$. Serial clinical assessments were conducted by the treating neurologist to define the clinical outcome.

\section{Results}

Forty seven female patients with proximal muscle weakness associated with Vitamin D deficiency were included. Their ages ranged between 13-46 years (mean 23.5, SD 4.5). Most patients $(81 \%)$ were living in the southern region of Saudi Arabia. All of the women were veiled and covered heavily when outside the house for social and cultural reasons. Only eight (17\%) had adequate varied diet with daily milk ingestion. All patients presented with progressive muscle weakness, proximal more than distal. The duration of their symptoms before our evaluation ranged between 6-24 months (mean 14). Osteomalcia was the referral diagnosis in 11 of these 47 patients. The remaining 36 (77\%) patients were misdiagnosed and referred to neurology or electromyography (EMG) for further evaluation of their weakness. Common misdiagnoses included orthopedic disorder, psychiatric disorders, and inherited myopathy. The proximal weakness was severe in six (13\%) patients leading to wheel chair bound states. The weakness was moderate in $22(42 \%)$ patients with significant restriction of activities of daily living, but with continued independent mobility. As well, difficulties in rising from a chair, inability to ascend stairs, and diffuse muscle pain were the main clinical symptoms in these patients. Other associated symptoms are summarized in the Table and included back pain, bone pain, carpopedal spasm, and growth deficiency. Four patients were previously diagnosed with celiac disease and two were chronically using carbamazepine for epilepsy. Family history of osteomalacia was positive in 11 patients (23\%).

Detailed laboratory investigations included complete blood count and differential, ESR, hepatic and renal profiles, thyroid function test, parathyroid hormone, serum calcium, phosphate, alkaline phosphatase, albumin, creatine phosphokinase, and 25hydroxy Vitamin D3. All patients had metabolic profile suggestive of osteomalacia with low-normal serum calcium $(\leq 2.1 \mathrm{mmol} / \mathrm{l})$, low serum phosphate $(\leq 0.7 \mathrm{mmol} / \mathrm{l})$, and high serum alkaline phosphatase $(>700 \mathrm{mmol} / \mathrm{l})$. Low 25 -hydroxy Vitamin D $(<20 \mathrm{nmol} / \mathrm{l})$ and high parathyroid hormone were documented in $90 \%$ of patients. The levels of these biochemical parameters did not correlate with the severity of muscle weakness. Creatine phosphokinase was normal in all patients. Radiologically, osteopenia was documented in $90 \%$ of patients and Looser zones (pseudofractures) were found in 13 (28\%) patients (four in the ribs, three in the pelvis, three in the femur, and three in the vertebrae). Nuclear medicine bone scans in 4 of these 13 patients showed homogenous tracer uptake in the skeleton with multiple focal areas of increased tracer activity representing Looser zones. Electromyography was performed on all patients and revealed increased insertional activity and small polyphasic waves suggestive of myopathic process. No fibrillation potentials were noted. Motor and sensory nerve conduction studies revealed normal distal latencies and conduction velocities. Muscle biopsy was performed in one patient, where the diagnosis was initially missed, and showed non-specific muscle fiber atrophy without degenerative changes. After establishing the diagnosis of osteomalacia, all patients were placed on oral cholecalciferol (800 IU/day) and calcium supplements (1200 mg/day). Follow-up assessment confirmed the remarkable recovery of their muscle strength and resolution of their other musculoskeletal symptoms within three months. Patients were followed for up to two years (mean 13 months, SD 4.6). After many months of disability, wheelchair bound patients were ambulating independently. Treatment was maintained for four to six months (mean 5.4) along with treatment of underlying etiologies.

\section{DisCUSSION}

Our study highlights that osteomalacia is an important treatable cause of proximal myopathy in young women. Such weakness is commonly missed or delayed and therefore may progress to a severe stage causing severe disability. Vitamin D deficiency is the most common cause of osteomalacia resulting 
Table: Presenting and associated clinical features of our patients

\begin{tabular}{lcc}
\hline Symptoms \& Signs & Number / Total & Percentage \\
Progressive proximal muscle weakness & $47 / 47$ & $100 \%$ \\
Gait disturbances & $47 / 47$ & $100 \%$ \\
Diffuse musculoskeletal pain (hips \& lower limbs) & $31 / 47$ & $66 \%$ \\
Back pain & $15 / 47$ & $32 \%$ \\
Carpopedal spasm & $6 / 47$ & $13 \%$ \\
Growth deficiency* & $3 / 47$ & $6 \%$ \\
\hline
\end{tabular}

* When both weight and height were 2 SD below the mean for age.

usually from limited sun exposure, dietary deficiency, or gastrointestinal disease ${ }^{11-14}$. Limited sun exposure occurs in the northern latitudes, home bound people, dark skinned individuals, heavy sunscreen users, and those who have limited exposure for social, cultural, or health reasons ${ }^{11-13}$. Excessive clothing and covering was the case in most of our patients $(81 \%)$, who lived in the less urbanized southern region of Saudi Arabia. This association was described by several authors ${ }^{15-17}$. Veiled women when compared to unveiled women with similar dietary habits were more likely to be Vitamin D deficient. Another study from Turkey compared the degree of veiling with the severity of Vitamin D deficiency and found a direct relationship ${ }^{18}$. The authors concluded that it was related to a combination of lack of sun exposure due to traditional dress, dark skin color, and poor dietary habits ${ }^{19}$. Only $17 \%$ of our patients had adequate varied diet. Malabsorption after gastric bypass, gastrectomy, or due to celiac disease is an important cause of osteomalacia ${ }^{20,21}$. Four of our patients were previously diagnosed with celiac disease. However, osteomalacia can be the presenting feature of celiac disease $\mathrm{e}^{22-23}$. These patients are more likely to develop osteomalacia if they were also sunlight-deprived ${ }^{24}$. In addition, two of our patients were on chronic carbamazepine therapy for epilepsy, which is known to accelerate hepatic degradation of Vitamin D and increase biliary excretion ${ }^{25,26}$. It is also possible that the osteomalacia in these patients resulted from combination of drug effect and poor dietary intake, coupled with lack of sun exposure. Other contributing factor in our cohort could be genetic as $23 \%$ had a positive family history of similar complaints. However, shared environmental and socio-cultural factors are the most likely etiology amongst these families.

Osteomalacia may present with diffuse musculoskeletal pain and muscle weakness ${ }^{27-29}$. The mechanism of weakness is not known, however, it is likely that high levels of parathyroid hormone, hypophosphatemia, and low levels of calcitriol all contribute. An elevation in serum alkaline phosphatase with a low-normal plasma calcium concentration are clues to the diagnosis ${ }^{30,31}$. However, the best laboratory indicator of Vitamin $\mathrm{D}$ adequacy is the serum 25-OH Vitamin D concentration as clinical myopathy may be present before the development of biochemical signs of bone disease. The serum creatine phosphokinase level is usually normal. Radiologically, reduced bone density with thinning of the cortex is the most common finding, which was seen in $90 \%$ of our patients. Looser zones (pseudofractures) are the characteristic radiologic finding in osteomalacia $^{32}$. They are fissures or narrow radiolucent lines with sclerotic borders lying perpendicular to the cortical margins, seen in $28 \%$ of our patients. Looser zones can also be seen more readily with bone scans where they appear as hot spots $^{32}$. This was documented in 4 of our 13 patients with Looser zones. The EMG is normal or may show mild "myopathic" motor unit potentials without fibrillations. Muscle biopsy is not indicated and if done, shows nonspecific findings including type2 muscle fiber atrophy ${ }^{33}$. The response to treatment in osteomalacic myopathy is dramatic. It was most remarkable in our wheel chair bound patients. After many months of disability, they were able to ambulate independently and function normally with a simple medical treatment.

There are several limitations to our study. Our sample was identified retrospectively from referrals to neurology or EMG services. Therefore, it is possible that our sample is not very representative as some patients may be missed or identified and managed by the primary care physician. However, our sample is large and varied. No men were included as this disorder is extremely uncommon in men because of adequate sun exposure. The socio-cultural factors causing females to excessively cover, do not apply to men in our region. Another limitation of our study is the lack of formal documentation of the actual muscle strength and its improvement post-therapy. However, all patients had significant weakness with dramatic recovery after treatment. We conclude that osteomalacia should be recognized as a treatable cause of myopathy with an excellent clinical outcome. The diagnosis is frequently delayed or missed. Screening for Vitamin D deficiency in patients with acquired myopathy is needed to identify this treatable disorder.

\section{ACKNOWLEDGMENT}

The authors thank Drs. N. Ashoor, Z. Mutair, O. Wazzan, and T. Obaid for participating with some of their referred patients. We also thank Prof. John Girvin for critically reviewing the initial manuscript. 


\section{REFERENCES}

1. Swash M, Schwartz MS, Sargeant MK. Osteomalacic myopathy: an experimental approach. Neuropathol Appl Neurobiol. 1979;5(4): 295-302.

2. Kaur K, Singh A, Prabhakar BR. Osteomalacic myopathy. J Indian Med Assoc. 1980;74(12):238-40.

3. Reginato AJ. Musculoskeletal manifestations of osteomalacia. Rev Rhum Engl Ed. 1997;64(6):107-13.

4. Skaria J, Katiyar BC, Srivastava TP, Dube B. Myopathy and neuropathy associated with osteomalacia. Acta Neurol Scand. 1975;51(1):37-58.

5. Sedrani SH. Low 25-hydrxy Vitamin D and abnormal calcium concentration in Saudi Arabia: Riyadh region. Ann Nutr Metab. 1984;28(3):181-5.

6. Sedrani SH, Elidrissy AWTH, Elarabi KM. Sunlight and Vitamin D status in normal Saudi subjects. Am J Clin Nutr. 1983;38:129-32.

7. Gullu S, Erdogan MF, Uysal AR, Baskal N, Kamel AN, Erdogan G. A potential risk for osteomalacia due to sociocultural lifestyle in Turkish women. Endocr J. 1998;45(5):675-8.

8. Holick MF. Sunlight and vitamin D for bone health and prevention of autoimmune diseases, cancers, and cardiovascular disease. Am J Clin Nutr. 2004;80(6):1678-88.

9. Al Faraj S, Al Mutairi K. Vitamin D deficiency and chronic low back pain in Saudi Arabia. Spine. 2003;28(2):177-9.

10. Bingham CT, Fitzpatrick LA. Noninvasive testing in the diagnosis of osteomalacia. Am J Med. 1993;95:519-23.

11. Plotnikoff GA, Quigley JM. Prevalence of severe hypovitaminosis $\mathrm{D}$ in patients with persistent, nonspecific musculoskeletal pain. Mayo Clin Proc. 2003;78(12):1463-70.

12. Holick MF. Vitamin D: a millennium perspective. J Cell Biochem. 2002; 88:269-307.

13. Kaplan FS, Soriano S, Fallon MD, Haddad JG. Osteomalacia in a night nurse. Clin Orthop Relat Res. 1986;205:216-21.

14. Finch PJ, Ang L, Eastwood JB, Maxwell JD. Clinical and histological spectrum of osteomalacia among Asians in South London. Q J Med. 1992;83:439-11.

15. Guzel R, Kozanoglu E, Guler-Uysal F, Soyupak S, Sarpel T. Vitamin D status and bone mineral density of veiled and unveiled Turkish women. J Women Health Gend Based Med. 2001;10(8):765-70.

16. El Sonbaty MR, Abdul-Ghaffar NU. Vitamin D deficiency in veiled Kuwaiti women. Eur J Clin Nutr. 1996;50(5):315-8.

17. Erkal MZ, Wilde J, Bilgin Y, Akinci A, Demir E, Bodeker RH, et al. High prevalence of Vitamin D deficiency, secondary hyperparathyroidism and generalized bone pain in Turkish immigrant in Germany: identification of risk factors. Osteoporos Int. 2006;17(8):1133-40.
18. Alagol F, Shihadeh Y, Boztepe H, Tanakol R, Yarman S, Azizlerli $\mathrm{H}$, et al. Sunlight exposure and Vitamin D deficiency in Turkish women. J Endocinol Invest. 2000;23(3):173-7.

19. Reed SD, Laya MB, Melville J, Ismail SY, Mitchell CM, Ackerman DR. Prevalence of vitamin D insufficiency and clinical associations among veiled East African women in Washington state. J Women's Health. 2007;16(2):206-13.

20. Berger JR. The neurological complications of bariatric surgery. Arch Neurol. 2004;61(8):1185-9.

21. Koffman BM, Greenfield LJ, Ali II, Pirzada NA. Neurologic complications after surgery for obesity. Muscle Nerve. 2006;33 (2):166-76.

22. Byrne MF, Razak AR, Leader MB, Sheehan KM, Patchett SE. Disabling osteomalacic myopathy as the only presenting feature of celiac disease. Eur J Gastroenterol Hepatol. 2002;14(11): 1271-4.

23. Kozanoglu E, Basaran S, Goncu MK. Proximal myopathy as an unusual presenting feature of celiac disease. Clin Rheumatol. 2005;24(1):76-8.

24. De Boer WA, Tytgat GN. A patient with osteomalacia as single presenting symptom of gluten-sensitive enteropathy. J Intern Med. 1992; 232:81-5.

25. Dent CE, Richens A, Rowe DJ, Stamp TC. Osteomalacia with longterm anticonvulsant therapy in epilepsy. Br Med J. 1970;4(5): 69-72.

26. Hoikka V, Alhava EM, Karjalainen P, Keränen T, Savolainen KE, Riekkinen P, et al. Carbamazepine and bone mineral metabolism. Acta Neurol Scand. 1984;70(2):77-80.

27. Russell, JA. Osteomalacic myopathy. Muscle Nerve. 1994;17: 578-11.

28. Glerup H, Mikkelsen K, Poulsen L, Hass E, Overbeck S, Andersen $\mathrm{H}$, et al. Hypovitaminosis D myopathy without biochemical signs of osteomalacic bone involvement. Calcif Tissue Int. 2000;66(6):419-24.

29. Pfeifer M, Begerow B, Minne HW. Vitamin D and muscle function. Osteoporos Int. 2002;13(3):187-94.

30. Russell JA. Osteomalacic myopathy. Muscle Nerve. 1994;17(6): 578-80

31. Bingham CT, Fitzpatrick LA. Noninvasive testing in the diagnosis of osteomalacia. Am J Med. 1993;95:519-22.

32. Kim S, Park CH, Chung YS. Hypophosphatemic osteomalacia demonstrated by Tc-99m MDP bone scan: a case report. Clin Nucl Med. 2000;25(5):337-40.

33. Frame B, Parfitt AM. Osteomalacia: current concepts. Ann Intern Med. 1978;89(6):966-82. 